\title{
Field Effect Transistor Device
}

National Cancer Institute

\section{Source}

National Cancer Institute. Field Effect Transistor Device. NCI Thesaurus. Code C49951.

A transistor designed so that current through it is controlled by a variable electric field. 